\title{
Maternal Outcome Following Uterine Rupture and Its Associated Factors Among Mothers Who Delivered at Felege-hiwot Referral Hospital, Amhara-Ethiopia
}

\author{
Alemtsehay Wesson, MSc. \\ Department of Midwifery, Wollo University, Dessie, Ethiopia \\ Enyew Assefa, MSc. \\ Department of Statistics, Wollo University, Dessie, Ethiopia
}

\begin{abstract}
Background: Ruptured uterus is one of the major causes of maternal and prenatal morbidities and mortalities in developing countries, particularly in Africa. Ethiopia is one of developing countries where maternal and prenatal mortalities are still high. The major objective of this study was to determine maternal outcomes of uterine rupture and its associated factors. Methods: The study design was facility based retrospective cross-sectional study from all mothers who visit from Sep, 1/2011 - Aug, 31/2015 at Felege-hiwot referral hospital delivery room for delivery service with ruptured uterus was conducted in the study. A total of 312 cases were enrolled in the study. The table, graph and binary logistic regression was found to be more appropriate for analyzing the data. Result: More than $39 \%$ mothers had severe complication. The common complication was severe anemia $24.4 \%$ followed by severe shock $14.7 \%$. There were also $2.7 \%$ maternal deaths. The binary logistic regression model showed that incidence and its complication of uterine rupture in this study were remarkably high. Antenatal care visit, duration of labor and admission to laparotomy time and hospital stay had strong association with maternal outcome. Conclusion: improving access to antenatal care, proper monitoring of labor and early referral of high risk patients will contribute to the reduction of unfavorable maternal outcome.
\end{abstract}

Keywords: Uterine Rupture, Maternal Outcome, Felege-hiwot Referral Hospital

DOI: $10.7176 / \mathrm{JBAH} / 9-5-07$

Publication date:March $31^{\text {st }} 2019$

\section{Introduction}

Uterine rupture refers to the complete nonsurgical disruption of all uterine layers (endometrium, myometrium, and serosa). There are two type of rupture; complete rupture involves the whole thickness of uterine wall and incomplete rupture occurs when serosa remain intact (Steven G. 2012). Rupture of gravid uterus occurs during the course of labor, intra-partum and post-partum. But in some cases it can occur during pregnancy without labor (Kelechi N. et al. 2013).

Sign and symptoms of uterine rupture depend on timing, site and extent of uterine defect. Those are fetal distress, cessation of contractions, abdominal tenderness, abdominal distension, palpable fetal parts, shock and vaginal bleeding. Site of rupture can be anterior, lateral, posterior, fundal or combination of two or more of those. And also it can be extended to adjacent structures like cervix, vagina and/or both (Kenneth J. et. al 2011).

Rupture of uterus also associated with maternal morbidities such as severe hemorrhage, bladder rupture, foot drop, psychological trauma, fistula and anemia and sterilized due to surgical intervention of hysterectomy, maternal death, non-reassuring fetal status and stillbirth (Ipyana H.2009).

Related to pregnancy and child birth every day approximately 830 women die from preventable causes. Ninety nine percent of all maternal death occur in developing countries. Although from 1990 to 2015 maternal mortality worldwide dropped by about $44 \%$, maternal mortality ratio in developing country is still high. In which Maternal mortality ratio in Worldwide is 303 per 100,000 live births, in developing country 239 per 100,000 live births, Africa 542 per 100,000 live births and in developed country 12 per 100,000 live births (WHO 2015).

Study done on Maternal and newborn outcomes following uterine rupture shows that among the 347 uterine rupture cases severe outcome was occurred in $86(25 \%)$ of cases. Maternal age and inter-delivery interval $<18$ months were factors associated with severe outcome of uterine rupture (M.K. Barger et.al 2012).

A five year retrospective study conducted at Christian Hospital in Nigerian in 2007, found a rupture rate of 14.6 per 1,000 births. Forty percent (28/70) of these cases of rupture occurred in unscarred uterus. Of those 3 $(10.7 \%)$ cases of uterine rupture occurred in women who were not in labor. The mean duration of labor was $25 \pm 25.3$. Place of laboring in TBA homes and prolonged labor were factors associated with uterine rupture (Kelechi N. et al. 2013).

A case control study was done to determine risk factors for ruptured uterus at mulago hospital kampala, uganda. The result shows that, factors associated with uterine rupture were low socio-economic status, aged 2029 years, distance more than $10 \mathrm{~km}$ from hospital, history of prolonged labor, previously delivered by Caesarean 
section, non-attendance of antenatal care, patient with referral paper, babies weighing more than 3,500gm and testing HIV positive (kampala I. 2010).

Retrospective cross sectional study done in Mizan Aman General Hospital Ethiopia from 2015 found that, there were a total of 8,509 hospital deliveries and 136 uterine rupture cases with incidence rate of $1.6 \%$ or 1 in 89 deliveries. Factors associated with maternal outcome of uterine rupture were hemoglobin level, shock before operation, ANC follow up, blood transfusion and re-laparotomy done (Mengestie M. 2016).

A study done in Tanzania showed that Subtotal hysterectomy was performed in $120(73.6 \%)$ cases while Repair with BTL was done in 20 (12.3\%) and repair without BTL was done in $20(12.3 \%)$ cases. There were 21 maternal deaths and 157 prenatal deaths giving case fatality rates of $12.9 \%$ and $96.3 \%$, respectively. Major obstetric hemorrhage $34.4 \%$ was the commonest maternal complication and all patients had blood transfusion. Other complications were sepsis $17.5 \%$, vesico-vaginal fistula $6.2 \%$ and minor bladder injuries $3.3 \%$ (Hussein K. et.al.2012).

Study conducted in Sudan in 2010 found that $69.7 \%$ of cases were management by repair of the uterus and $12.1 \%$ repair with BTL. Subtotal hysterectomy was performed in $12.1 \%$ and total hysterectomy constituted $6.1 \%$. Common complications were severe blood loss that necessitated blood transfusion in $18.2 \%$ of cases, critical ill that needed ICU in $81.8 \%$ cases, bladder injury in $36.4 \%$ of cases, hysterectomy in $18.2 \%$ of cases, postoperative hyperpyrexia in $12.1 \%$ of cases and wound infection constituted $6.1 \%$ of cases (Mohamed A. et.al. 2010).

Prospective Study done at Debre Marekose hospital found that Operation time ranges from 40-150 minutes with average of 77 minutes. Admission to laparotomy time was from 2-10 hours. Total abdominal Hysterectomy was performed for $77.1 \%$ of cases followed by repair with or without BTL $18.6 \%$ and subtotal abdominal hysterectomy for $4.3 \%$ of cases. In $58.6 \%$ of cases blood was transfused and average duration of hospital stay was 10 days. The case fatality rate was $21.4 \%$ (15/70) (A. Admassu 2004).

Study done in Adigrat hospital reported that at admission 51(95.4\%) had signs of uterine rupture and while in $3(5.6 \%)$ rupture occurred in hospital. Fifty three percent was transfused with blood, 16.7\% had postoperative wound infection and $12.5 \%$ had vesico vaginal fistula. Maternal case fatality rate was $11.1 \%$ and fetal case fatality rate was $98.1 \%$. Ruptured uterus contributed $24 \%$ of all causes of maternal deaths in the hospital within the study period (Gessessew A. 2002).

The underlying factors for rupture include delay in seeking appropriate care at the onset of labor, a poor or non-existent referral system, non-attendance of antenatal care and delayed interventions due to a combination of factors especially the lack of skilled human resources and medical consumables (Ezechi M. and Obiesie LO. 2004).

The occurrence of uterine rupture varies in different parts of the world. It is rare in high-income countries in which the risk of maternal death due to uterine rupture is $0-1 \%$. But it remains a public health problem in low income countries, particularly in Africa, Case fatality rates ranges between $1-13 \%$ and about $75 \%$ of cases of uterine rupture occurred in women with an unscarred uterus following obstructed labor [WHO 2010 and A. Admassu 2004).

In Ethiopia maternal mortality is 353 per 100,000 live births and Majority of maternal deaths take place during childbirth and the immediate postpartum period. The top four causes of maternal mortality were obstructed labor/uterine rupture $36 \%$ followed by hemorrhage, hypertensive disorders of pregnancy and sepsis/infection [WHO 2015 and Yifru B. 2014).

However there was paucity of information on factors associated with maternal outcome of uterine rupture in Ethiopia and there was no study conducted in the study area. Therefore, this study was aimed at determining maternal outcome of uterine rupture and its associated factors at Felege-hiwot referral hospital during the study period.

\section{Methods and materials \\ 2.1 Study area}

The study was conducted in Bahir-Dar administration city. It is the capital city of Amhara national regional state (ANRS), which is located about $565 \mathrm{~km}$ northwest of Addis Ababa. The city has one referral hospital, one district hospital, ten health centers, ten health posts, two private hospitals, and higher clinics. Among private institution only two hospitals and two nongovernmental clinics are providing delivery. Felege-hiwot referral hospital is the only governmental referral hospital in the city. The hospital gives service for an estimated of 7 million people from Bahir-Dar city, East and west Gojjam, Awi ,south and north Gondor zones and Metekel zone of Benshangul Gumuz regional state with different in- patient and out-patient wards. Felege-hiwot referral hospital has seven wards with 627 professional and 161 administrative staffs. Specifically the hospital has its' own well equipped maternity ward which possesses around 60 beds for serving different activities. In the hospital, on average there are about 6500 women delivered on each physical year (FRH 2015).

\subsection{Study design and Data Collection}

In this study facility based retrospective cross-sectional study design was conducted. All mothers who visit Felege- 
hiwot referral hospital delivery room for delivery service with ruptured uterus from September, 1/2011 - August, $31 / 2015$ was conducted in the study. There were 375 mothers admitted and managed for uterine rupture in the 5 years of study period but only $312(83.2 \%)$ mothers were complete information and we collected the data from these women while the remaining 63(16.8\%) women were incomplete information and we were excluded these mothers from the study.

\subsection{Study variables}

The response variable of this study was maternal outcome of uterine rupture (favorable outcome or unfavorable outcome uterine rupture).

Explanatory variables expected to associate maternal outcome of uterine rupture were age, address, antenatal care follow up, duration of labor, occurrence of the rupture, admission to laparotomy time, duration of the procedure, type of rupture and hospital stay. Working definitions of these socio-demographic and obstetrical explanatory descriptions are provided in the appendix 1 .

\subsection{Operational definitions}

Uterine rupture: defined as complete or incomplete nonsurgical disruption of uterine layers (endometrium, myometrium, and serosa) diagnosed and confirmed after laparotomy.

Unfavorable outcome: A mother who had one or more of the following complication: Who had severe shock, severe anemia (hemoglobin level $<7 \mathrm{gm} / \mathrm{dl}$ ), transfused $\geq 3$ units of blood, having fistula, re-laparotomy done, hysterectomy without having alive child, maternal death.

\subsection{Data processing and analysis}

Data collection format were checked for completeness, coded and entered in to EPI INFO version 3.5.2 statistical software and then transported to SPSS windows version 20 for further analysis. Errors related to inconsistency of data was checked and corrected during data cleaning. Descriptive statistics such as percentages, frequency distributions and appropriate graphic presentation were used for describing the data.

Binary logistic regression was used to assess association and strength of association between explanatory factors and outcome variable. In the study Hosmer- Lemeshow test and Likelihood ratio test were used to assess the goodness of fit of the model. If p-value for the Hosmer-Lemeshow goodness of fit test was greater than 0.05 , we would not reject the null hypothesis that there was no difference between observed and model predicted values, implying that the model estimates were adequate to fit the data at an acceptable level (Hosmer and Lemeshow, 2000).

\section{Result}

\subsection{Distribution of Unfavorable Maternal Outcome}

The common complication for unfavorable maternal outcome of uterine rupture was anemia (97.4\%) and $24.4 \%$ had severe anemia. While blood transfusion was given to $73.1 \%$ and $9.9 \%$ of cases transfused more than three units of blood. Another causes considered as influencing the unfavorable maternal outcome of uterine rupture was vesico-vaginal fistula (7.7\%). In addition, $14.7 \%$ of mothers had severe shock. There were also $2.7 \%$ maternal deaths. Re-laparotomy was done for $7.4 \%$ outcome of uterine rupture cases (Table 1 ).

Table 1: Distribution of unfavorable Outcome of uterine rupture at Felege-hiwot referral hospital

\begin{tabular}{|l|l|l|}
\hline Post-operative complication & Frequency N=312 & Percent \\
\hline Anemia & 304 & 97.4 \\
\hline Severe anemia & 76 & 24.4 \\
\hline Blood transfused & 228 & 73.1 \\
\hline Transfusion more than three units & 31 & 9.9 \\
\hline Vesico-vaginal fistula & 24 & 7.7 \\
\hline Severe shock & 46 & 14.7 \\
\hline Surgical site infection & 21 & 6.7 \\
\hline Re-laparotomy done & 23 & 7.4 \\
\hline Maternal death & 10 & 2.7 \\
\hline
\end{tabular}

\subsection{Outcome of Uterine Rupture across Socio-demographic and obstetrical Factors}

The total number of women covered in the study was 312 . Among these, $39.7 \%$ unfavorable maternal outcome of uterine rupture and also $81.5 \%$ resided in rural areas. The majority $62.1 \%$ unfavorable maternal outcome of uterine rupture were in the adult mothers (19-35years). With regard to antenatal care follow up, $41.1 \%$ no antenatal cares follow up were unfavorable outcome of uterine rupture. Another variable considered was duration of labor during delivery. Accordingly, approximately half (49.2\%) of unfavorable outcome of uterine rupture had greater 
than 24 hour's duration of labor during delivery. Similarly, more than half (54\%) proportion of unfavorable outcome of uterine rupture was $\geq 40$ minutes taken to laparotomy. The highest $(91.1 \%)$ proportion of unfavorable outcome of uterine rupture was occurred before arriving at hospital. The frequent site for unfavorable outcome of uterine rupture was lateral rupture (35.5\%) followed by lower uterine segment $(33.9 \%)$ (Table3). Regarding to the type of surgical intervention total abdominal hysterectomy was performed for $66 \%$ of cases followed by uterine rupture without BTL (15.1\%). While 5.1\% had bladder rupture and repaired successfully (Figure 1).

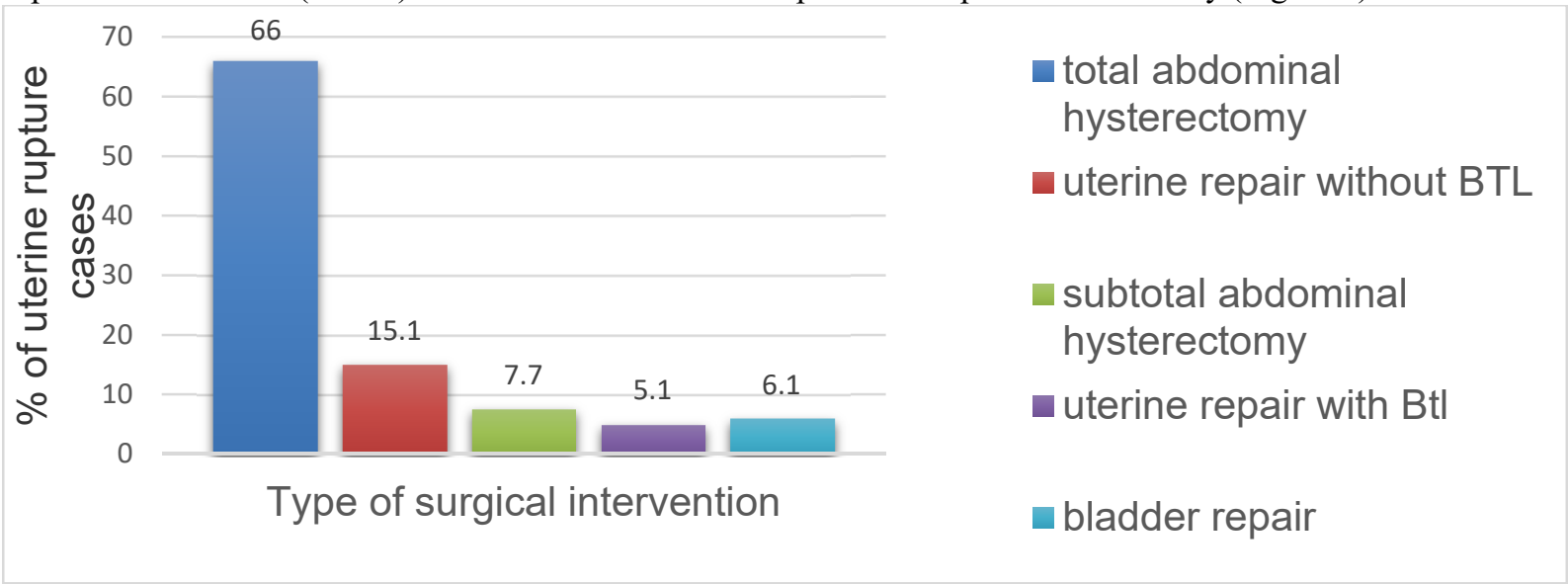

Figure 1: Type of surgical interventoin at Felege-hiwot referral hospital

\subsection{Model Analysis of Maternal Outcome of Uterine Rupture}

Binary logistic analysis was done to assess association between maternal outcome of uterine rupture variable and explanatory variables. The explanatory variables in the model were women's age, address, antenatal care follow up, duration of labor, occurrence of the rupture ,admission to laparotomy time, duration of the procedure, type of rupture and hospital stay.

\subsubsection{Model fitting}

Hosmer and Lemeshow test was used to assess a goodness of fit test of the null hypothesis that the model adequately fits the data, since the value of the Hosmer-Lemeshow goodness-of-fit test statistic significance value was greater than 0.05 (i.e.0.652>0.05), we fail to reject the null hypothesis that there was no difference between observed data and model-predicted values, implying that the model fitted the data at an acceptable level, this proved that the predicted data were not significantly different from the observed data (Table 2).

Consider the model which included all predictors. Omnibus Tests of Model Coefficients had given ChiSquare value of 12.065 which was significant at 5\% level of significant. Since our omnibus test was significant we can concluded that adding the predictors to the model had significantly increased our ability to predict maternal outcome of uterine rupture (Table 2).

Table 2: Hosmer and Lemeshow Test, and Omnibus Tests of Model Coefficients

\section{Hosmer and Lemeshow Test}

\begin{tabular}{|c|c|c|c|c|}
\hline Step & & Chi-square & $\mathrm{df}$ & Sig. \\
\hline $\begin{array}{l}1 \\
2\end{array}$ & & $\begin{array}{l}.000 \\
.204\end{array}$ & $\begin{array}{l}0 \\
1\end{array}$ & .652 \\
\hline \multicolumn{5}{|c|}{ Omnibus Tests of Model Coefficients } \\
\hline 1 & $\begin{array}{l}\text { Step } \\
\text { Block } \\
\text { Model }\end{array}$ & $\begin{array}{l}7.048 \\
7.048 \\
7.048 \\
\end{array}$ & $\begin{array}{l}1 \\
1 \\
1\end{array}$ & $\begin{array}{l}.008 \\
.008 \\
.008 \\
\end{array}$ \\
\hline 2 & $\begin{array}{l}\text { Step } \\
\text { Block } \\
\text { Model }\end{array}$ & $\begin{array}{r}5.017 \\
12.065 \\
12.065\end{array}$ & $\begin{array}{l}2 \\
3 \\
3\end{array}$ & $\begin{array}{l}.081 \\
.007 \\
.007\end{array}$ \\
\hline
\end{tabular}

\subsection{Factors Associated with Maternal Outcome of Uterine Rupture}

The result of fitted model showed that the outcome of uterine rupture mothers who had labor duration during delivery more than 24 hour had 2.89 times unfavorable outcome than those uterine rupture mothers who had labor duration less than 24 hour while holding all other variables in the model constant. The model also revealed that antenatal care follow up had a statistically significant impact on maternal outcome of uterine rupture. Mothers who had not attended antenatal care follow up had 2.62 times unfavorable outcome than those mothers 
who had antenatal care follow up while holding all other variables in the model constant. Mothers who were managed with laparotomy after 40 minutes of diagnosis had 2.34 times more likely to had unfavorable outcome than those mothers who were managed with laparotomy within 40 minutes of diagnosis. The uterine rupture mothers who came from urban were 1.15 times unfavorable outcome compared to that of the mothers who came from rural area. With regarding to the age of mothers the fitted model showed that adult mothers had a significant influence on the unfavorable maternal outcome of uterine rupture. Also mothers who were stay greater than or equal to eight days in the hospital had 4.48 times unfavorable outcome than that of mothers who stay less than eight days in the hospital while holding all other variables in the model constant (Table 3).

Table 3: Fitted model of maternal outcome of uterine rupture at Felege-hiwot Referral Hospital.

\begin{tabular}{|c|c|c|c|c|c|}
\hline \multirow[t]{2}{*}{ Variable } & \multicolumn{2}{|c|}{ Maternal outcome } & \multirow[t]{2}{*}{ COR $(95 \%$ CI) } & \multirow[t]{2}{*}{$\operatorname{AOR}(95 \% \mathrm{CI})$} & \multirow[t]{2}{*}{$\mathrm{p}$-value } \\
\hline & $\begin{array}{l}\text { Unfavorable } \\
\mathrm{N}=124(\%)\end{array}$ & $\begin{array}{l}\text { Favorable } \\
\mathrm{N}=188(\%)\end{array}$ & & & \\
\hline \multicolumn{6}{|l|}{ Age } \\
\hline$<18$ years & $11(8.9)$ & $9(4.8)$ & $2.27(1.28,3.93)$ & $2.50(0.74,8.87)$ & 0.082 \\
\hline 19-35years & $77(62.1)$ & $143(76.0)$ & $1.85(1.08,3.18)$ & $1.61(0.80,3.26)$ & $0.024 *$ \\
\hline$\geq 35$ years & $36(19.0)$ & $36(19.2)$ & 1 & 1 & \\
\hline \multicolumn{6}{|l|}{ Address } \\
\hline Rural & $101(81.5)$ & $124(65.9)$ & $2.27(1.31,3.90)$ & $1.15(0.54,2.48)$ & $0.03 *$ \\
\hline Urban & $23(18.5)$ & $64(34.1)$ & 1 & 1 & \\
\hline \multicolumn{6}{|l|}{ ANC follow up } \\
\hline No & $51(41.1)$ & $45(23.9)$ & $2.22(1.36-3.62)$ & $2.62(1.40,4.91)$ & $0.01 *$ \\
\hline Yes & $73(58.9)$ & $143(76.1)$ & 1 & 1 & \\
\hline \multicolumn{6}{|l|}{ Duration of labor } \\
\hline$\geq 24$ hours & $61(49.2)$ & $45(23.9)$ & $3.07(1.89,5.00)$ & $2.89(2.55,5.37)$ & $0.001^{*}$ \\
\hline$<24$ hours & $63(50.8)$ & $143(76.1)$ & 1 & 1 & \\
\hline \multicolumn{6}{|c|}{ Occurrence of rupture } \\
\hline Out of hospital & $113(91.1)$ & $179(95.2)$ & $0.51(0.22,1.28)$ & $0.97(0.28,3.34)$ & 0.15 \\
\hline At hospital & $11(8.9)$ & $9(4.8)$ & 1 & 1 & \\
\hline \multicolumn{6}{|c|}{ Admission to laparotomy time } \\
\hline$\geq 40$ minutes & $67(54.0)$ & $73(38.9)$ & $1.85(1.17,2.93)$ & $2.34(1.28,4.26)$ & $0.009 *$ \\
\hline$<40$ minutes & $57(46.0)$ & $115(61.1)$ & 1 & 1 & \\
\hline \multicolumn{6}{|c|}{ Duration of the procedure } \\
\hline$\geq 120$ minutes & $25(20.1)$ & $27(14.4)$ & $1.5(0.88,2.71)$ & $1.7(0.76,3.79)$ & 0.18 \\
\hline$<120$ minutes & 99(79.9) & $161(85.6)$ & 1 & 1 & \\
\hline \multicolumn{6}{|l|}{ Type of rupture } \\
\hline $\begin{array}{l}\text { LUS with } \\
\text { extension to } \\
\text { adjacent organs }\end{array}$ & $29(23.4)$ & $30(16.0)$ & $1.97(1.01,3.74)$ & $1.27(0.56,2.88)$ & 0.34 \\
\hline Lateral & $44(35.5)$ & $56(29.8)$ & $1.6(0.93,2.76)$ & $1.06(0.50,2.29)$ & 0.85 \\
\hline Posterior & $9(7.2)$ & $16(8.5)$ & $1.15(0.47,2.82)$ & $1(0.31,3.20)$ & 0.75 \\
\hline $\begin{array}{ll}\text { Lower } & \text { uterine } \\
\text { segment } & \end{array}$ & $42(33.9)$ & $86(45.7)$ & 1 & 1 & \\
\hline \multicolumn{6}{|l|}{ Hospital stay } \\
\hline$\geq 8$ days & $66(53.2)$ & $46(24.5)$ & $3.51(2.16-5.70)$ & $4.48(2.40,8.34)$ & $0.001 *$ \\
\hline$<8$ days & $58(46.8)$ & $142(75.5)$ & 1 & 1 & \\
\hline
\end{tabular}

* Significant at $5 \%$ level of significance

\section{Discussion}

Rupture of the gravid uterus is catastrophic obstetric complication that is associated with high maternal and prenatal mortality rates particularly in developing countries.

In this study, there were excesses unfavorable outcome uterine rupture cases. The leading cause of unfavorable outcome was anemia $97.4 \%$, about $73 \%$ of cases transfused with blood and severe shock $14.7 \%$. This was slightly higher when compared to studies done in Mizan Aman Ethiopia 93\% had anemia and 51.3\% transfused with blood (Mengestie H. 2016).

The result of this study also indicated that there were $2.7 \%$ maternal deaths. Which was lower than in Adigrat Ethiopia (Gessessew A. 2002), Debre Marekose Ethiopia (A.Admassu 2004) and Tanzania (HusseinK.et.al. 2012) were $11.1 \%, 21.4 \%$ and $12.9 \%$ respectively, probably this difference in maternal outcome reflects difference in 
quality of maternal health care providers and availability of emergency care services in different countries.

According to result of this study uterine rupture mothers who had labor duration more than 24 hour had more likely to had unfavorable outcome than those uterine rupture mothers who had labor duration less than 24 hour. The probable reason might be the possibility of obstruction which leads to further exhaustion and highly exposure to infection which leads to further complication. This finding is consistent with the finding by (Kelechi N. et al. 2013) and (kampala I. 2010).

Mothers who had not attended antenatal care follow up had unfavorable outcome than those mothers who had antenatal care follow up. The probable reason might be those mothers with no antenatal care follow up had lack of information about danger signs of pregnancy and they might delay to go to health facilities and they were not supplemented with iron during pregnancy so the severity of anemia would be high. This finding was agreed with studies conducted in Mizan Aman Ethiopia (Mengestie H. 2016), (Ezechi M. and Obiesie LO. 2004) and (kampala I. 2010).

Mothers who were managed with laparotomy after 40 minutes of diagnosis had more likely to had unfavorable outcome than those mothers who were managed with laparotomy within 40 minutes of diagnosis. The probable reason might be once the uterus ruptured the bleeding might be continued until the bleeding sight was secured by surgical intervention. So if the time gap increases the mother might deteriorate.

This study also revealed that the unfavorable outcome was higher for mothers aged 19-35years (adult mothers) than mothers in the other age groups. Which was similar finding studied by (kampala I. 2010) and (M.K. Barger et.al 2012).

\section{Conclusion}

The incidence and its complication of uterine rupture were remarkably high. Important causative factors were cephalopelvic disproportion, mal-presentation, in general neglected or obstructed labor was the commonest cause. According to the finding of this study antenatal care follow up, duration of labor, admission to laparotomy time, address of mothers and hospital stay were important predictors of maternal outcome.

\section{Recommendation}

Assigning a responsible person on this referral hospital, who can assess the gap of obstetric problems daily, address feedbacks for referral cases and reporting for responsible person.

The staff should be well-equipped and organized to manage these emergency obstetric complications quickly including blood transfusion, laparotomy and resuscitation measures.

Improving labor follow up with parthograph and timely decision for cesarean sections of abnormal labor.

Efforts need to be intensified to work together to break geographical and cultural barriers which could result in unnecessary dalliance of the community in seeking and reaching care in the health facility and they should also make proper community mobilization and education to increase awareness of the society towards antenatal care and delivery at health institution.

Prospective studies focusing on the determinants factors of this obstetric problem which is helpful in designing interventional activities targeted at improving institutional delivery service utilization, intrapartal close follow up of labor and early referral of high risk mothers.

\section{References}

Steven G.gabbe (2012). Obstetrics normal and problem solving,6th edition, England, McGraw-Hill Company.

Kelechi N. Eguzo1, Chisara C. Umezurike (2013). Rupture of unscarred uterus: a multi-year cross-sectional study from Nigerian Christian Hospital. Nigeria: Int J Reprod Contracept Obstet Gynecol;2 (4):657-660.

Kenneth.J, Judis S, etal (2011). Obstetrics complication's William's obstetrics, $23^{\text {rd }}$ edition,New York, McGrawHill Company.

Ipyana Hudson. five year retrospective analysis of the cause, complication,fetomaternal out come Tanzania.muhimbili university of health and allied science, march 2009.

WHO UaWB. traiend in maternal mortality 1990-2015 estimates developed by WHO,UNICEF,UNFPA and World Bank:Jeneva:World Health Organization, 2015.

M K. Barger, et al. Severe maternal and prenatal outcomes from uterine rupture among women at term with a trial of labor. Am J ObstetGynecol; Sep;2012, California, USA.184(7):1576-81.

Kampala, I. prevalence, predisposing factors and outcomes Ruptured uterus. Uganda: Singapore Med J; 2010;51(1): 35-38.

Mengestie. HMaB. Maternal and Perinatal Outcomes of Uterine Rupture Patients among Mothers who Delivered at Mizan Aman General Hospital, SNNPR, South West Ethiopia; MOJ Womens health. 2016;2(1).

Hussein. K, Ipyana, M and Jos van. R. Uterine rupture: a retrospective analysis of causes, complications and management outcomes at Muhimbili National Hospital in Dar es Salaam, Tanzania. Journal of Health Research; July 2012; 14 (3). 
Mohamed. A, Ahmed. M, Ghayda. E, etal. Rupture Uterus in Sudanese Women:Management and Maternal complication. World Journal of Pharmacy and Pharmaceutical Sciences.2010; 4(04).

A.Admassu. Analysis of uterine rupture in debre markose hospital. MD East African Medical Journal;2004; 81(1):53-5.

Gessessew. A MM. Ruptured uterus - eight year retrospective analysis of causes and management outcome in Adigrat Hospital, Tigray Region, Ethiopia. Ethiop J Health Dev 2002;16:241.

Ezechi OC M, Obiesie LO. Rupture uterus in south east Nigeria a reappraisal. Singapore Med J;2004;45:113-6.

WHO. Trends in maternal mortality 1990 to 2008. Estimates developed by WHO, UNICEF, UNFPA and the world bank Geneva: WHO Press;2010.

Yifru Berhan AB. cause of maternal mortality in Ethiopia:a significant decline in abortion related death. Ethiop J Health Sci; September 2014

Felegehiwot Referal Hospital annual report. 2015.

Hosmer, D. W. and Lemeshow, S. (2000). Applied Logisitc Regression. New York: John Wiley \& Sons, Inc.

\section{APPENDIX}

Appendix 1: Defintion and categories of working explanatory variables

\begin{tabular}{|l|l|l|}
\hline No. & Variable & Categories \\
\hline $\mathbf{1}$ & Age & $0=<18$ years (younger mothers) \\
& & $1=19-35$ years (adult mothers) \\
& & $2=\geq 35$ years (older mothers) \\
\hline $\mathbf{2}$ & Address & $0=$ Rural \\
& & $1=$ Urban \\
\hline $\mathbf{3}$ & ANC follow up & $0=$ No \\
& & $1=$ Yes \\
\hline $\mathbf{4}$ & Duration of labor & $0=\geq 24$ hours \\
& & $1=<24$ hours \\
\hline $\mathbf{5}$ & Occurrence of the rupture & $0=$ Out of hospital \\
& & $1=$ At hospital \\
\hline $\mathbf{6}$ & Admission to laparotomy time & $0=\geq 40$ minutes \\
& & $1=<40$ minutes \\
\hline $\mathbf{7}$ & Duration of the procedure & $0=\geq 120$ minutes \\
& & $1=<120$ minutes \\
\hline $\mathbf{8}$ & Type of rupture & $0=$ LUS with extension to adjacent organs \\
& & $1=$ Lateral \\
& & $2=$ Posterior \\
& & $3=$ Lower uterine segment \\
\hline $\mathbf{9}$ & Hospital stay & $0=\geq 8$ days \\
& & $1=<8$ days \\
\hline
\end{tabular}

